Cationic niosome-based hBMP7 gene transfection of neuronal precursor NT2 cells to reduce the migration of glioma cells in vitro. Attia, N., Mashal, M., Grijalvo, S., Eritja, R., Puras, G., Pedraz, J.L. J. Drug Delivery Science Technol., 53 (2019) $101219 . \quad$ Doi: 10.1016/j.jddst.2019.101219

\title{
Cationic niosome-based hBMP7 gene transfection of neuronal precursor NT2 cells to reduce the migration of glioma cells in vitro
}

\author{
Noha Attia a,b,c,1, Mohamed Mashal ${ }^{a, 1}$, Santiago Grijalvo d,e, Ramón \\ Eritja $^{\mathrm{d}, \mathrm{e}}$, Gustavo Puras ${ }^{\mathrm{a}, \mathrm{d}, *},{ }^{*}$ J ose Luis Pedraz ${ }^{\mathrm{a}, \mathrm{d},{ }^{* *}}$
}

${ }^{a}$ NanoBioCel Group, Laboratory of Pharmaceutics, School of Pharmacy, University of the Basque Country (UPV/EHU), Paseo de la Universidad 7, 01006, Vitoria-Gasteiz, Spain

${ }^{b}$ Histology and Cell Biology Department, Faculty of Medicine, University of Alexandria, Alexandria, Egypt

'Department of Basic Sciences, The American University of Antigua-College of Medicine, Coolidge, Antigua and Barbuda

${ }^{\mathrm{d} N e t w o r k i n g ~ R e s e a r c h ~ C e n t r e ~ o f ~ B i o e n g i n e e r i n g, ~ B i o m a t e r i a l s ~ a n d ~ N a n o m e d i c i n e ~}$ (CIBER-BBN), Vitoria-Gasteiz, Spain

Institute for Advanced Chemistry of Catalonia (IQAC-CSIC), Spain

* Corresponding author. Laboratory of Pharmacy and Pharmaceutical Technology, School of Pharmacy, University of the Basque Country, 01006, Vitoria-Gasteiz,

**Corresponding author. Laboratory of Pharmacy and Pharmaceutical Technology, School of Pharmacy, University of the Basque Country, 01006, Vitoria-Gasteiz,

Spain.

E-mail addresses: Noha.Attia@alexmed.edu.eg (N. Attia), Mashal313@yahoo.com (M. Mashal), sgrgma@cid.csic.es (S. Grijalvo), recgma@cid.csic.es (R. Eritja), gustavo.puras@ehu.eus (G. Puras), joseluis.pedraz@ehu.eus (J.L. Pedraz).

${ }^{1}$ Both authors contributed equally to this work.

https://doi.org/10.1016/j.jddst.2019.101219

Keywords: Glioblastoma, Gene therapy, hBMP7, Niosomes, NT2 cells

ABSTRACT. This study explores interesting complementary approaches in cellbased hBMP7 gene delivery in order to mitigate the migration of glioblastoma cells based on the idea that this human bone morphogenetic protein (hBMP7) has enormous therapeutic potential in curing brain injuries as well as malignancies. After physicochemical characterization, the non-viral cationic niosomes were complexed with pUNO1-hBMP7 plasmids and used to transfect neuronal precursor NT2 cells. Subsequently, the transfected cells were co-cultured with glioma C6 cells to determine their antitumor effect in vitro. However the co-culture with either untransfected/transfected NT2 cells may reduce the viability of C6 glioma cells, the hBMP7-overexpressing NT2 cells hamper the migration of C6 glioma cells. These results highlight the potential of NT2 cell-based delivery of hBMP7 for impeding the metastasis of glioma cells.

\section{I ntroduction}

Glioblastoma multiforme (GBM), the most aggressive primary intracranial tumor, is well-known for its high mortality rate and poor treatment outcomes [1]. 
The average survival time of patients following surgery combined with chemotherapy and/or radiotherapy, is less than 12 months. Therefore, therapeutic approaches are still needed to fight this devastating disease. During gliomagenesis, the tumor-suppressive activity of transforming growth factor- $\beta$ (TGF- $\beta$ ) signaling pathway is generally perturbed, leading to malignant progression [2].

The human bone morphogenetic protein 7 (hBMP7), a member of the transforming growth factor $\beta$ superfamily, plays a pivotal role in the development of bone, kidney and nervous tissues [3]. Interestingly, exposure to BMP7 can induce canonical BMP signaling in stem-like glioblastoma cells, in vitro [4]. The ability of BMP7 to induce the differentiation of brain tumor stem cells is accompanied by the attenuation of stem-like marker expression and reduction of self-renewal. Currently, the in vivo delivery methods of BMP7 are basically through multiple local and/or intravenous injections of the recombinant hBMP7. Unlike some other growth factors, BMPs have a short half-life, are not particularly soluble and seem to act locally, so the aforementioned delivery routes are often ineffective [5], and need multiple injections. Nevertheless, in sensitive tissues such as brain tissue, repeated injections could lead to inevitable tissue damage. Therefore, alternative approaches for supplying BMP7 to glioma cells are needed to circumvent the negative aspects of conventional therapies. Amongst those promising alternatives are those based on cell/gene delivery. More specifically, human neuronal precursor NT2 cells exhibit two ideal characteristics for cancer gene therapy; they have tumor-selective migratory capacity and they can be genetically manipulated to express selected therapeutic genes [6]. As gene delivery systems, non-viral vectors have gained attention over the years, in comparison to their counterparts, the viral-based vectors [7,8]. Non-viral gene carriers are not as limited by the size of the transferred genes and they have a lower immunogenicity and oncogenic profile. These appealing features make non-viral gene carriers potential candidates for commercialization because of how easy it is to produce them and also because there are less hurdles to overcome in terms of meeting the regulatory standards.

As non-viral gene carriers, cationic niosomes are osmotically active selfassembled vesicles made up of cationic lipids and non-ionic surfactants. They are better than liposomes in terms of cost effectiveness and chemical stability, and have received increasing attention over time as potential gene delivery vehicles $[9,10]$.

In our recent study [11], we developed a novel cationic niosome gene carrier based on chemical compounds (the cationic lipid 2,3-ditetradecyloxypropanlamine, the non-ionic surfactants poloxamer 188 and polysorbate 80) demonstrating flattering properties for gene delivery applications [12]. Our previous results obtained with reporter GFP plasmids, in vitro/vivo, have encouraged us to proceed with the current study in which we aimed to provide a proof-of-concept of whether NT2 cells could be used as a model for hBMP7 gene expression in order to combat glioma cell migration. We initially transfected NT2 cells with DPP80- hBMP7 nioplexes and then we investigated their potential "combined" antitumor effect on C6 glioma cell line, in vitro.

\section{List of used abbreviations:}

hBMP7 Human bone morphogenetic protein7

CM Conditioned media

GBM Glioblastoma multiforme

L2K Lipofectamine ${ }^{\circledR} 2000$

OC Open circular

SC Supercoiled

SD Standard deviation

TGF- $\beta$ Transforming growth factor- $\beta$ 


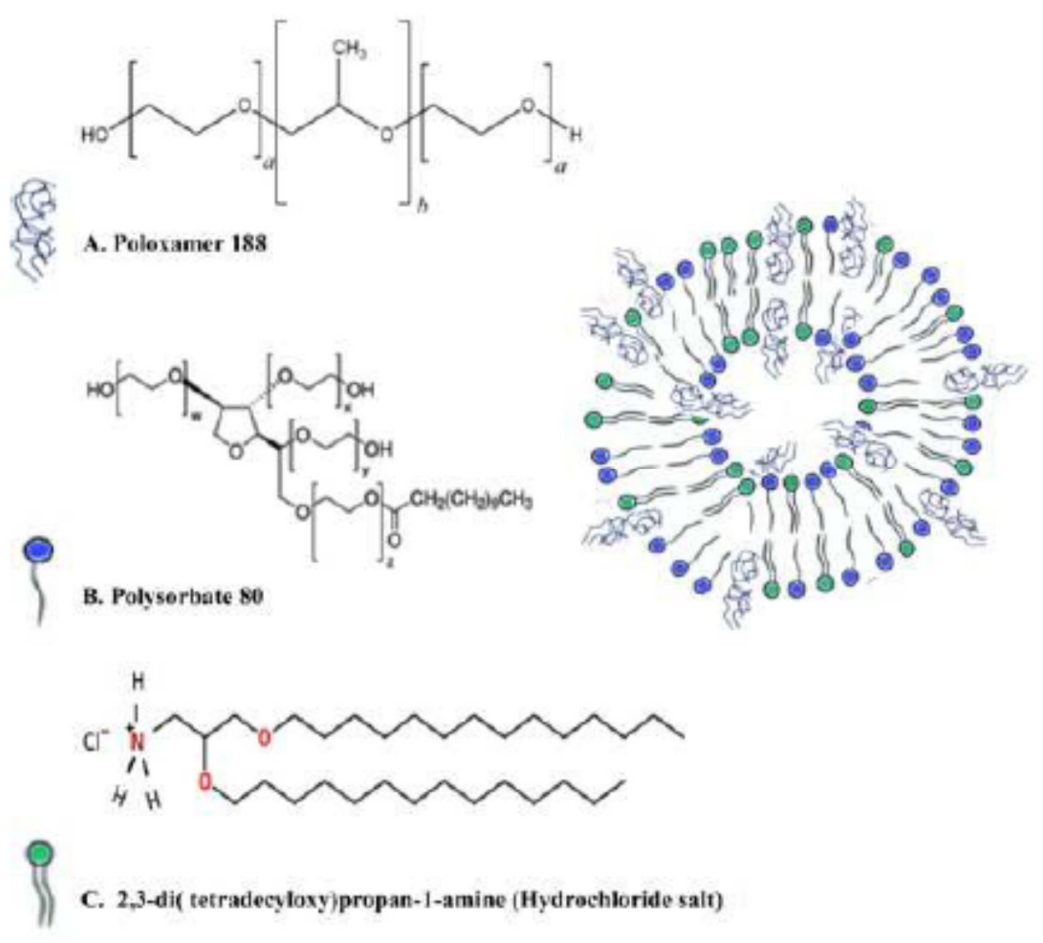

Fig. 1. Chemical structure of: A) Poloxamer 188 (P), B) Polysorbate 80 (P80), and C) Cationic lipid [2,3-di(tetradecyloxy)propan-1-amine] (D).

\section{Material and methods}

\subsection{Material}

Human teratocarcinoma NTERA2/D1(NT2) $\left(\right.$ ATCC $^{\circledR}-\mathrm{CRL}, 1973$ ) and the rat glioma cell line (C6, CCL-107) were purchased from the American Type Culture Collection (ATCC, Manassas, VA, USA). C6 cells were grown in the ATCC-formulated F-12K Medium (Catalog No. 30-2004). Dulbecco's Modified Eagle's Medium (DMEM, ATCC $30-2002$ ), trypsin, Fetal bovine Serum (FBS) were purchased from Gibco ${ }^{\circledR}$ (San Diego, California, US). Opti-MEM ${ }^{\circledR}$ reduced medium, Lipofectamine ${ }^{\circledR} 2000$ transfection reagent, antibiotics $[100 \mathrm{U} / \mathrm{ml}$ penicillin and $100 \mu \mathrm{g} / \mathrm{ml}$ streptomycin (Pen/Strep)] were acquired from Gibco ${ }^{\circledR}$ (Life Technologies S.A., Madrid, Spain). Cell counting (CCK-8) viability/ proliferation assay and crystal violet were obtained from Sigma Aldrich (Madrid, Spain). GelRed ${ }^{\circledR}$ solution was obtained from Biotium (Hayward, California, USA), while other materials for gel electrophoresis were obtained from Bio-Rad (Madrid, Spain). pUNO1-hBMP7 plasmid $(0.5 \mathrm{mg} / \mathrm{ml}$ ) was obtained from InvivoGen (Toulouse, France). Sodium dodecyl sulfate (SDS), DNasel, polysorbate 80, poloxamer 188, and PBS were purchased from Sigma Aldrich (Madrid, Spain). Uncoated Transwell ${ }^{\circledR} 24$ well microplates with $8.0 \mu \mathrm{m}$ pore size (Costar-Corning, Corning, NY). 


\subsection{Preparation of niosome vesicles}

The cationic lipid 2,3-di (tetradecyloxy)propan-1-amine hydrochloride (D) was synthesized by slightly modifying the experimental protocol previously described [13]. Afterward, niosomes were manufactured by modifying the reverse phase evaporation technique as discussed earlier [14]. Briefly, the cationic lipid (5 $\mathrm{mg}$ ) was dissolved in dichloromethane $(1 \mathrm{ml})$, and then emulsified in $5 \mathrm{ml}$ of nonionic surfactant "equal weight \% of polysorbate 80 (P80) and poloxamer 188 (P). The emulsion was obtained by sonication (Branson Sonifier $250^{\circledR}$, Branson Ultrasonics Corporation, Danbury, USA) at $45 \mathrm{~W}$ for $30 \mathrm{~s}$. After evaporating the dichloromethane, the resulting niosomes were referred to as DPP80 (components shown in Fig. 1).

\subsection{Preparation of DPP80-hBMP7 nioplexes}

The niosome/DNA complexes (nioplexes) were obtained by mixing an appropriate volume of a stock solution of pUNO1-hBMP7 plasmid $(0.5 \mathrm{mg} / \mathrm{ml})$ with different volumes of niosome suspensions ( $1 \mathrm{mg}$ cationic lipid/ml) in order to obtain different cationic lipid/DNA ratios $(\mathrm{w} / \mathrm{w})$. The mixture was incubated for $30 \mathrm{~min}$ at room temperature to ensure electrostatic interactions.

\subsection{Assessment of DPP80-hBMP7 nioplexes' features}

Dynamic light scattering (DLS) and Laser Doppler Velocimetry (LDV) (Zetasizer Nano ZS, Malvern Instruments, UK) were used to determine the particle size and zeta potential (ZP), respectively. Particle size was obtained using cumulative analysis where all measurements were carried out in triplicate.

Nioplexes were examined by via cryo-TEM (TECNAI G2 20 TWIN), operating at an accelerated voltage of $200 \mathrm{KeV}$ in a bright-field and low dose image mode [15]. The acquired digital images were used to assess the nioplexes' morphology. The niosomes' potential to condense, liberate and protect the pUNO1-hBMP7 plasmid DNA against enzymatic digestion was evaluated using an agarose gel retardation assay. The naked and niosome-complexed DNA samples (200 ng of plasmid/20 $\mathrm{\mu l}$ ) were run on an agarose gel $(0.8 \% \mathrm{w} / \mathrm{v})$. The tris-acetate-EDTA bufferimmersed gel was later exposed to $120 \mathrm{~V}$ for $30 \mathrm{~min}$. In order to analyze the release of DNA from nioplexes at different cationic lipid/DNA mass ratios, $20 \mu \mathrm{l}$ of the SDS solution (2\%) were added/sample. The supposed nioplexes-induced protection for DNA against DNase I enzymatic digestion was assessed by adding $1 \mathrm{U}$ DNase $1 / 2.5 \mu \mathrm{g}$ DNA. Subsequently, mixtures were incubated at $37^{\circ} \mathrm{C}$ for $30 \mathrm{~min}$ followed by adding a SDS solution (like above) to release DNA from the nioplexes. The resulting bands were stained with GelRed $^{\mathrm{TM}}$ and visualized by ChemiDoc ${ }^{\mathrm{TM}}$ MP I maging System (Bio-Rad, Madrid, Spain).

\subsection{In vitro culture and transfection of NT2 cells}

NT2 cells (ATCC $\left.{ }^{B}-C R L, 1973\right)$ were cultured in a growth medium composed of; Dulbecco's Modified Eagle's Medium (DMEM), 10\% fetal bovine serum (FBS) and antibiotics $(100 \mathrm{U} / \mathrm{ml}$ penicillin and $100 \mu \mathrm{g} / \mathrm{ml}$ streptomycin. The night before transfection, NT2 cells were seeded in 24 -well plates at an initial density of $8 \times 104$ cells/well and allowed to proliferate up to $70-80 \%$ confluence. The medium was then replaced with serum-free Opti-MEM, and cells were exposed to the nioplexes at a concentration of $1.25 \mu \mathrm{g}$ of pUNO1-hBMP7/well. After $4 \mathrm{~h}$ of incubation, the serum-free transfection medium was replaced with the growth medium. $24 \mathrm{~h}$ later, conditioned media (NT2-CM) was collected, filtered ( $0.22 \mu \mathrm{m}$ filters) and preserved at $-80{ }^{\circ} \mathrm{C}$ until ELISA was performed to determine the hBMP7 secreted. Cell counting (CCK-8) viability/ proliferation assay was carried out as previously reported [16]. The color development was read at $450 \mathrm{~nm}$ (Tecan M200 microplate reader), corrected with reference wavelength at $690 \mathrm{~nm}$, and normalized against blank wells. The positive control, Lipofectamine ${ }^{\circledR} 2000$ was prepared following the manufacturer's transfection protocol. 


\subsection{In vitro culture and proliferation assay of $\mathrm{C} 6$ glioma cells}

The rat glioma cell line (C6, CCL-107) was grown in the ATCCformulated F12K Medium (Catalog No. 30-2004). To make the growth medium (GM), fetal bovine serum was added to a final concentration of $2.5 \%$, horse serum to a final concentration of $15 \%, 100 \mathrm{U} / \mathrm{ml}$ of penicillin, and $100 \mu \mathrm{g} / \mathrm{ml}$ of streptomycin. Cells were maintained at a humidified atmosphere at $37{ }^{\circ} \mathrm{C}$ with $5 \% \mathrm{CO}_{2}$ and were used at the third passage.

In 24 multiple-well culture plates, C6 cells were seeded ( 100.000 cells/well) overnight. The next day, GM was replaced with NT2-CM, both untransfected (+NT2) and transfected (+NT2-hBMP7). The C6-CM was prepared as mentioned in section 2.4. After $24 \mathrm{~h}$, cell proliferation was determined using CCK8 assay according to the manufacturer's instructions. The wells where NT2-CM was added were compared to "control" C6 glioma cells wells grown on C6-CM.

\subsection{Co-culture and transwell migration assays}

The glioma cell migration assay was carried out using uncoated Transwell ${ }^{\circledR}$ 24 well microplates with $8.0 \mu \mathrm{m}$ pore size. About 80.000 NT2 cells (of untransfected/transfected cultures ( $24 \mathrm{~h}$ post-transfection) were seeded in the lower chambers and incubated at $37^{\circ} \mathrm{C}$ for $4 \mathrm{~h}$ to ensure cell attachment. Then, $\mathrm{C} 6$ glioma cells (in $200 \mu \mathrm{l}$ serum free media) were seeded in the upper Transwell insert ( 100.000 cells/insert). $16 \mathrm{~h}$ later, the medium was aspirated, and non-migratory cells were removed by swabbing the interior of the insert wells using cottontipped swabs. The migrating C6 cells on the lower surface of the Transwell ${ }^{\circledR}$ membranes were fixed in methanol, stained with crystal violet $(0.09 \%$ crystal violet) and counted under an inverted optical microscope (Nikon TSM). Five random fields were counted for each membrane, and the mean values from three independent experiments, performed in triplicate, were used.

\subsection{Statistical analysis}

Statistical differences between groups (significance levels of $>95 \%$ ) were calculated using ANOVA and Student's t-test. The values of $\mathrm{P}<0.05$ were regarded to be significant. Samples' normal distribution and homogeneity of the variance were evaluated with the Kolmogorov-Smirnov and the Levene tests, respectively. All numerical data were presented as mean \pm SD.
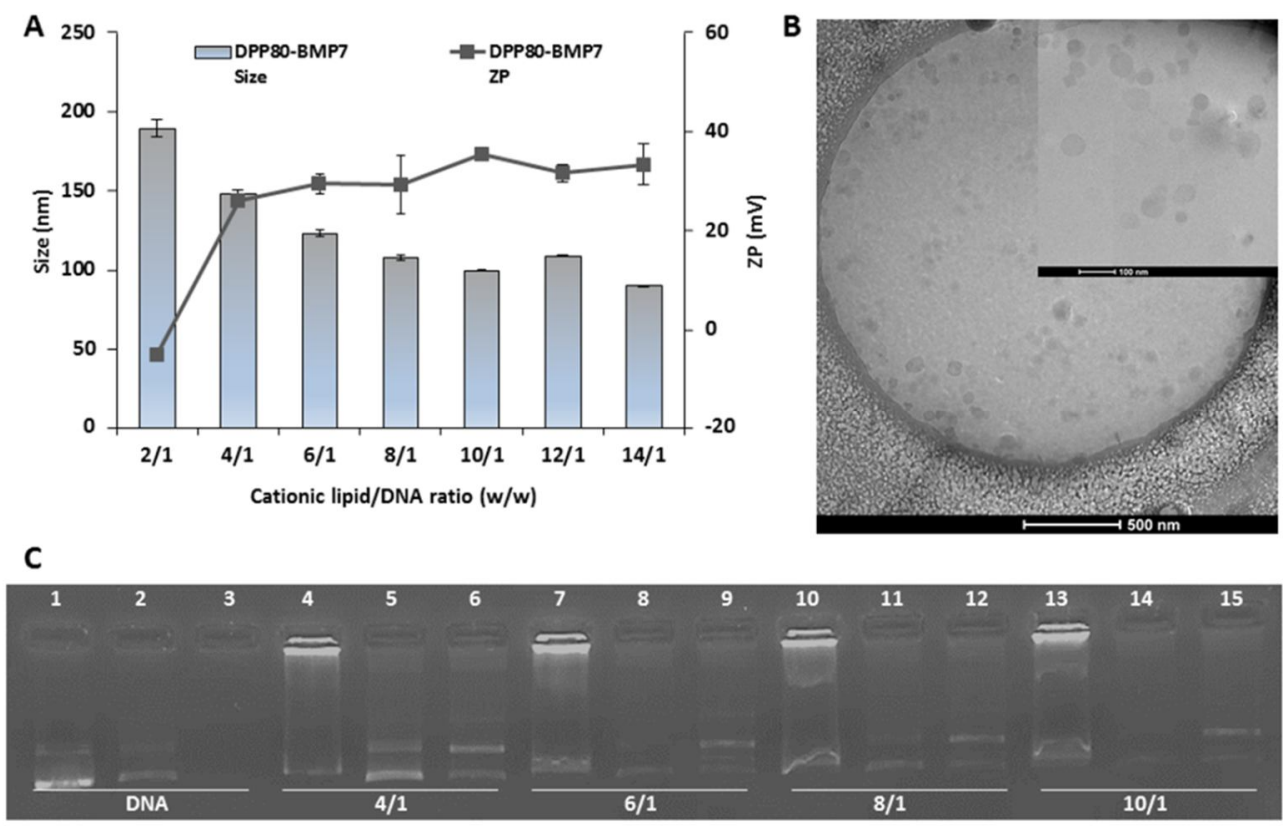

Fig. 2. A) Particle size $(n m)$ and Zeta potential $(m V)$. Data represent mean $\pm S D(n=3)$. B) Cryo-TEM micrographs of nioplexes at 6/1 cationic lipid/DNA mass ratio. Scale bar $500 \mathrm{~nm}$ 
(inset, $100 \mathrm{~nm}$ ). C) Gel retardation assay of nioplexes. Lanes 2, 5, 8, 11 and 14 depict nioplexes treated with SDS, while lanes 3, 6, 9, 12 and 15 correspond to DNase I- and SDStreated nioplexes. OC and SC: open circular and supercoiled forms, respectively.

\section{Results}

\subsection{Physicochemical features of niosomes/ nioplexes}

Fig. 2-A depicts both size and ZP assessment of DPP80-hBMP7nioplexes at mass ratios $2 / 1$ through $14 / 1$. The size of nioplexes (bars) gradually decreased from $190 \mathrm{~nm}$ to $90 \mathrm{~nm}$ at cationic lipid/DNA mass ratios of $2 / 1$ and $14 / 1$, respectively. With regard to surface charge, ZP readings gradually increased from $-5.2 \mathrm{mV}$ at $2 / 1$ mass ratio to $+35.5 \mathrm{mV}$ at $10 / 1$ mass ratio without any notable change thereafter. As illustrated in Fig. 2-B, the cryo-TEM-examined nioplexes (6/1 mass ratio) depicted imperfect spherical particles. Fig. 2-C represents gel retardation assay of nioplexes prepared at different cationic lipid/DNA ratios (4/1, $6 / 1,8 / 1$ and $10 / 1$ ). Such nioplexes demonstrated satisfactory ability to hold DNA, since most of the DNA signal was observed in the corresponding wells $(4,7,10$ and 13 lanes), and only faint SC bands were observed. Interestingly enough, the restrained DNA was liberated upon adding SDS, since no clear bands were observed in wells 5, 8, 11 and 14. Moreover, the DNA was protected from the DNase I enzyme, since clear OC (open circular) and SC (supercoiled) bands were detected in the 6th, 9th, 12th and 15th lanes, compared to the 3rd lane (free DNA).
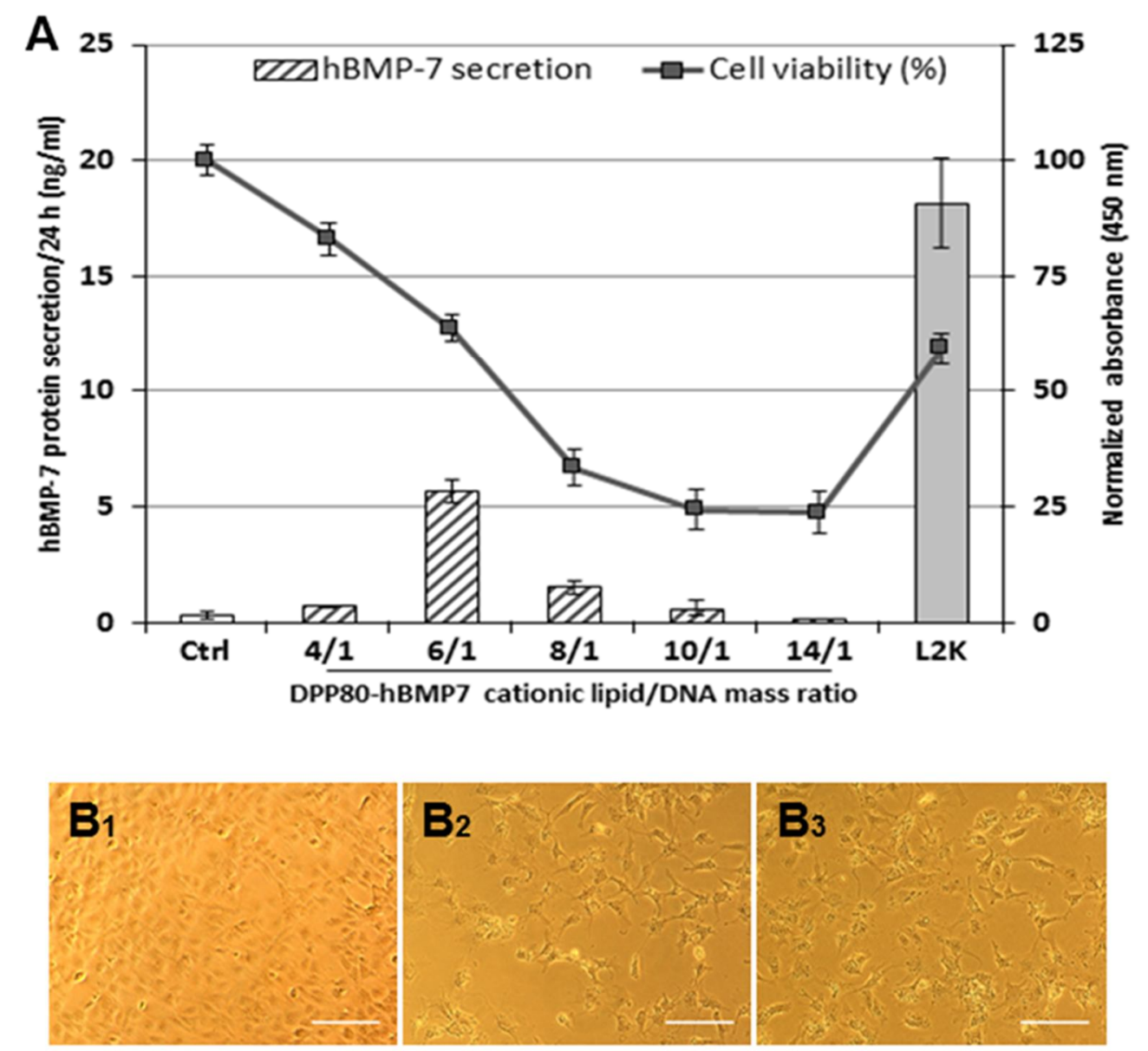

Fig. 3. (A) hBMP7 secretion ( $\mathrm{ng} / \mathrm{ml})$ at $24 \mathrm{~h}$ (bars). Values represent mean $\pm \mathrm{SD}(\mathrm{n}=3)$. *P $<0.05$ versus L2K. (B) Phase contrast micrographs of NT2 cells $24 \mathrm{~h}$ post-transfection (B1) control, (B2) hBMP7-DPP80-transfected, (B3) hBMP7-L2K-transfected cells. (Scale bars=50 $\mu \mathrm{m})$. 


\subsection{I n vitro transfection of NT2 cells}

The secretion of hBMP7 by transfected/untransfected NT2 cells at $24 \mathrm{~h}$ post transfection is observed in Fig. 3-A (bars). Throughout the studied cationic lipid/DNA mass ratios, the ratios of $6 / 1$ and $8 / 1$ depicted significant secretion of hBMP7 in comparison to the untransfected "ctrl" cells $(p<0.05)$. The ratio of $6 / 1$ was the highest transfection results $(5.7 \mathrm{ng} / \mathrm{ml})$, although it was still inferior to the secretion obtained by L2K transfection $(18 \mathrm{ng} / \mathrm{ml}, \mathrm{p}<0.05)$. On the other hand, CCK8 assay demonstrated that cell viability was almost inversely related to the mass ratio of cationic lipid/DNA (Fig. 3, line graph). At the mass ratio of $6 / 1$, peak of hBMP7 secretion, cell viability was still higher than that of L2K $(63.6 \%$ and $59.5 \%$, respectively, $* p<0.05)$. Control NT2 cells were epithelial-like adherent cells (Fig. 3-B1). One-day post-transfection, cells treated with DPP80 or L2K formulations, appeared more polyhedral with elongated processes (Fig. 3-B2 and 3B3, respectively).

\subsection{I n vitro proliferation assay of $\mathbf{C 6}$ glioma cells}

In order to measure the functionality of secreted hBMP7 on glioma cells, rat C6 glioma cells were treated with the conditioned media of untransfected (NT2-CM) and transfected (NT2-hBMP7-CM) cells. The NT2-CM significantly inhibited the cell growth of $\mathrm{C} 6$ cells, whether transfected (+NT2-hBMP7-CM) or untransfected (+NT2$\mathrm{CM})$ when compared to the C6-CM $(* \mathrm{P}<0.05)$ (Fig. 4). However, the antiproliferative effect of the CM retrieved from transfected and untransfected NT2 cells was almost the same $(P>0.05)$.

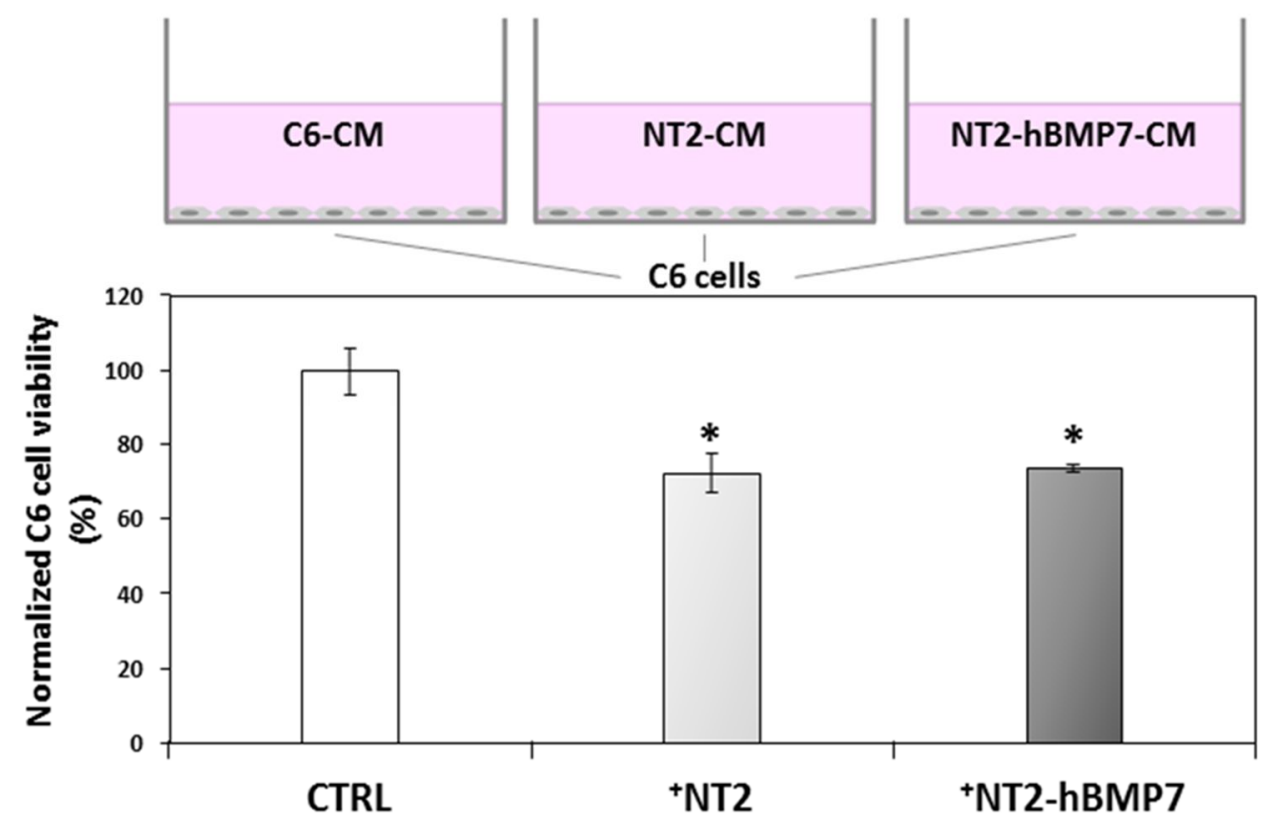

Fig. 4. In vitro viability assay of $\mathrm{C} 6$ glioma cells after incubation with; $\mathrm{C} 6-\mathrm{CM}$, untransfected NT2 cells and transfected NT2 cells. ( $* P<0.05)$.

\subsection{Transwell migration assay of $\mathbf{C 6}$ glioma cells}

Subsequently, the effect of hBMP7 secretion on C6 glioma cell migration was evaluated. As seen in Fig. 5, the migration of $C 6$ cells was notably less (*P $<0.05$ ) when co-cultured with transfected NT2 cells (+NT2-hBMP7) compared to the untransfected cells $(+\mathrm{NT2})$.

\section{Discussion}


The high mortality rate and aggressiveness in GBM patients has necessitated the search for novel, safe, and effective therapeutic approaches. Over the past few years, both cell and gene therapies have offered great promise in this realm.

In this study, we aimed to investigate the effectiveness of the newly synthesized cationic niosomes (DPP80) for transfecting NT2 cells, thus obtaining hBMP7-overexpressing NT2 cells. Such cationic niosomes were electrostatically complexed with the negatively charged pUNO1- hBMP7 plasmid rendering nioplexes at different cationic lipid/DNA mass ratios. Despite the lack of consensus over the optimal size of nonviral gene carriers, it is widely accepted that the particle size clearly affects their performance. In the current work, the size of nioplexes was clearly affected by the cationic lipid/DNA mass ratio (Fig. 2-A). At the mass ratio of $2 / 1$, the size was almost $190 \mathrm{~nm}$. Alongside higher mass ratios, the size gradually decreased, and this was most likely due to the electrostatic interactions that condense DNA plasmids more tightly. Not only their size, but the shape of non-viral complexes can also affect their final performance in gene delivery [3]. Our complexes were not perfectly regular in shape (Fig. 2-B) which could be due to the incorporation of non-ionic surfactants on the surface of niosomes. As well, the discrete morphology of nioplexes at $6 / 1$ mass ratio (Fig. 2-B) may be attributed to the high positive surface charge $(>29 \mathrm{mV})$, which in turn evades the particles' aggregation through electrostatic repulsion [17]. The electrostatic interactions between the DNA (negatively charged phosphate groups) and the cationic niosomes (positively charged amine groups) play a crucial role during the transfection process as a precise balance between DNA capture and release needs to be achieved [18]. To investigate that parameter, gel retardation assay was carried out (Fig. 2-C). We selected nioplexes at cationic lipid/DNA mass ratios higher than $2 / 1$ since the values of ZP were within the positive range (Fig. 2-A, lines). Interestingly, at all studied cationic lipid/DNA ratios, the niosomes were not only able to partially condense and totally release DNA upon adding SDS in all the cationic lipid/DNA mass ratios tested, but also to protect DNA against the enzymatic digestion, which is of significance in relevant in vivo applications. 

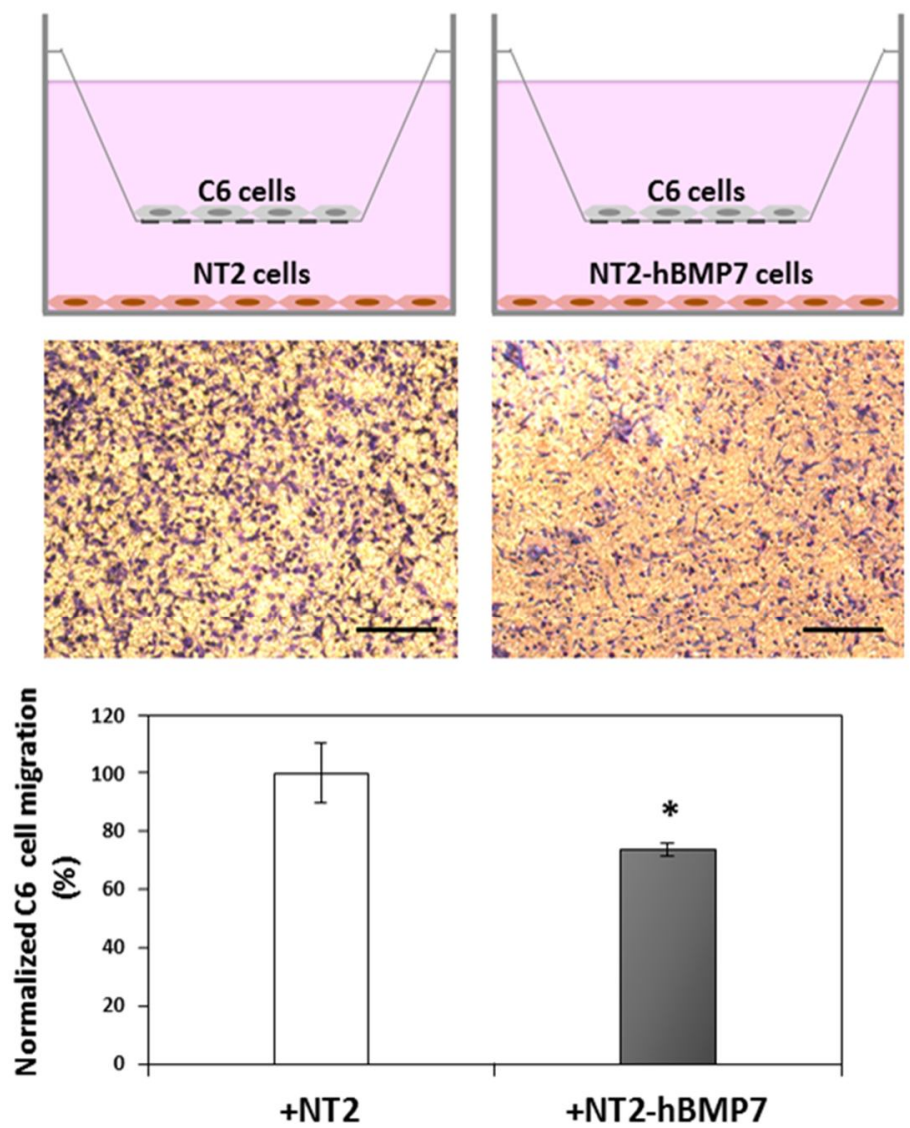

Fig. 5. Transwell migration assay of glioma C6 cells co-cultured with transfected NT2 cells $(+$ NT2-hBMP7) compared to the untransfected cells $(+N T 2)(* P<0.05)$. C6 glioma cells on the lower surface of Transwell inserts were stained with crystal violet (scale bar $=50 \mu \mathrm{m}$ ).

Thanks to the previously mentioned desirable characteristics of DPP80hBMP7 nioplexes, we went on to carry out an in vitro transfection study in order to evaluate the capacity of nioplexes to deliver pUNO1-hBMP7 plasmid into NT2 cells. Besides being regarded as a stable cell line suitable for transfection studies, NT2 cells have been reported to be a promising source of human cells in CNS-targeted cell therapy applications [19]. Interestingly, NT2 cells have successfully induced recovery in pre-clinical stroke models. Therefore, they have been endorsed in several clinical trials [20]. In particular, their intrinsic glioma-tropism has opened up new avenues for brain malignancy therapeutics. NT2 cells are advantageously amenable to scale-up cell production, thus might represent a delivery vehicle for cancer therapy [21]. The transfection data (Fig. 3) revealed the release of significant amount of hBMP7 $(5.7 \mathrm{ng} / \mathrm{ml}$ ) at the mass ratio of $6 / 1$ (cationic lipid/ DNA) where the cytotoxicity on NT2 cells was less compared to positive control L2K $(p<0.05)$. These results suggest that the BMP7-secreting NT2 cells could be used as an interesting platform for further in vivo studies on the nervous tissue as well as other tissues where the production of BMP7 is desired. Despite the comparatively low level of hBMP7 secretion $(5.7 \mathrm{ng} / \mathrm{ml})$ by transfected NT2 cells, a markedly low dose of hBMP7 (1 $\mathrm{ng} / \mathrm{ml}$ ) could increase SMAD phosphorylation 5-6 fold, thus having a significant therapeutic effect [5]. A low, yet continuous dose of hBMP7 expression could be both neuroprotective and differentiation-inductive [22]. Similarly, our research team has recently reported a marked impact of hBMP7 production, even at much lower expression values, to induce spontaneous 
osteogenic differentiation of mesenchymal stem cells [3]. Interestingly, a dose of $1.3 \mathrm{ng} / \mathrm{ml}$ of hBMP7 was enough to enhance the alkaline phosphatase activity and osteogenic matrix deposition, suggesting the effectiveness of such low concentrations of hBMP7 to achieve appropriate biological activities [5]. We then proceeded to evaluate the outcome of NT2-expressed hBMP7 on glioma cells. C6 glioma cells are stable, in vitro and in vivo, and express glioma-specific markers [23]. Thereafter, they are widely used in experimental studies for the treatment of gliomas [24]. An indirect co-culture system by culturing tumor C6 cells in the CM of NT2 cells was adopted to avoid the drawbacks of the direct co-culture system. In particular, the difficulty to evaluate the effect of one type of cells on another type. The overexpression of hBMP7 can alter the NT2 gene expression and suppress their own tumorigenicity, making them a safe candidate for in vivo studies [25]. Moreover, activation of BMP7 signaling in glioma cells could render them more vulnerable, and thereby more sensitive to low doses of chemotherapeutic drugs [26].

In accordance with Li and colleagues [27], the anti-glioma effect of NT2-CM could be mediated by the inactivation of mitogen activated protein kinase (MAPK) pathway. On the other hand, we observed (Fig. 4) that the overexpression of hBMP7 "per se" did not add any inhibitory effect on the viability of C6 cells. This effect could most probably be attributed to the presence of anti-BMP signals in the remaining serum content of NT2-CM, such as cytokines, noggin or chordin. The main goal of most antitumor drugs is to reduce cancer cell viability. However, because of the hyper-mutability of GBM cells, adjuvant anti-migration strategies are also desirable.

Among others, Chirasani and co-workers [28] have reported, in agreement with our findings, the ability of BMP7-expressing neural precursor cells to attenuate the tumorigenicity of glioblastoma cells as well as to induce glioma stem cell differentiation [29]. Regarding the observed suppression of migration effect, it should be noted that BMP7 may have contradictory effects depending on the cell line being investigated [30]. The discerned anti-migratory effects of hBMP7transfected NT2 cells (Fig. 5) could be attributed to the negative effect of hBMP7 on cell motility (across uncoated Transwell filters) [31] or to the induction of tumor stem cell differentiation/senescence [26]. Thus, further studies on the exact mechanism are still required.

This study represents a proof of concept that NT2 cells could be transfected with hBMP7 expression plasmids using the DPP80 cationic niosome gene carrier. Subsequently, the tumor-suppressive effects of hBMP7-expressing NT2 cells were investigated on the glioma cell line $\mathrm{C} 6$. The current preliminary data suggest that the NT2 cell-based gene delivery of hBMP7 could be further explored in animal models as a novel therapeutic approach to inhibit the proliferation and migration of gliomas. Adequate understanding of the underlying mechanisms is necessary for the development of effective cellular delivery vehicles for glioma therapy.

\section{Conflicts of interest}

The authors report no conflicts of interest in this work.

\section{Acknow ledgements}

This project was supported by the Basque Country Government (CGIC10/172), The Spanish Ministry of Education (Grant CTQ2014-52588-R), the Generalitat de Catalunya (2014/SGR/624) and the Instituto de Salud Carlos III (CB06_01_0019, CB06 01 1028). The authors also wish to thank the intellectual and technical assistance from the ICTS "NANBIOSIS", more specifically by the Drug Formulation Unit (U10) of the CIBER at Bioengineering, Biomaterials, and Nanomedicine (CIBER-BBN) at the University of Basque Country (UPV/EHU). Technical and human support provided by SGIker (UPV/EHU) is gratefully acknowledged.

\section{Appendix A. Supplementary data}


Supplementary data to this article can be found online at https:// doi.org/10.1016/j.jddst.2019.101219.

\section{References}

[1] C. Giannini, J.N. Sarkaria, A. Saito, J.H. Uhm, E. Galanis, B.L. Carlson, et al., Patient tumor EGFR and PDGFRA gene amplifications retained in an invasive intracranial xenograft model of glioblastoma multiforme, Neuro Oncol. 7.2 (2005) 164- 176 https://doi.org/10.1215/S1152851704000821.

[2] A.W. Nana, P.M. Yang, H.Y. Lin, Overview of transforming growth factor $\beta$ superfamily involvement in glioblastoma initiation and progression, Asian Pac. $J$. Cancer Prev. APJCP $16 \quad$ (16) (2015) 6813-6823 https: //doi.org/10.7314/APJ CP.2015.16.16.6813.

[3] N. Attia, M. Mashal, S. Grijalvo, R. Eritja, J. Zárate, G. Puras, et al., Stem cellbased gene delivery mediated by cationic niosomes for bone regeneration, Nanomedicine 14 (2) (2018) 521-531 https://doi.org/10.1016/j.nano.2017.11.005. [4] C. Tate, R. Pallini, L. Ricci-Vitiani, M. Dowless, T. Shiyanova, G. D'alessandris, et al., A BMP7 variant inhibits the tumorigenic potential of glioblastoma stem-like cells, Cell Death Differ. 19 (10) (2012) 1644 https://doi.org/10.1038/cdd.2012.44. [5] D.W. Chitty, R.G. Tremblay, M. Ribecco-Lutkiewicz, J. Haukenfrers, B. Zurakowski, B. Massie, et al., Development of BMP7-producing human cells, using a third generation lentiviral gene delivery system, J. Neurosci. Methods 205 (1) (2012) 17-27 https://doi.org/10.1016/j.jneumeth.2011.12.007.

[6] A.U. Ahmed, N.G. Alexiades, M.S. Lesniak, The use of neural stem cells in cancer gene therapy: predicting the path to the clinic, Curr. Opin. Mol. Ther. 12 (5) (2010) 546-552 PMID: 20886386 PMCID: PMC2958255.

[7] S. Grijalvo, G. Puras, J. Zárate, M. Sainz-Ramos, N.A. Qtaish, T. López, M. Mashal, N. Attia, D. Díaz, R. Pons, E. Fernández, Cationic niosomes as non-viral vehicles for nucleic acids: challenges and opportunities in gene delivery, Pharmaceutics 11.2 (2019) 50 https://doi.org/10.3390/pharmaceutics 11020050.

[8] M. Mashal, N. Attia, G. Martínez-Navarrete, C. Soto-Sánchez, E. Fernández,

S. Grijalvo, R. Eritja, G. Puras G, J.L. Pedraz, Gene delivery to the rat retina by nonviral vectors based on chloroquine-containing cationic niosomes, J. Control. Release 304 (2019) 181-190 https://doi.org/10.1016/j.jconrel.2019.05.010.

[9] M. Mashal, N. Attia, G. Puras, G. Martinez-Navarrete, E. Fernandez, J.L. Pedraz, Retinal gene delivery enhancement by lycopene incorporation into cationic niosomes based on DOTMA and polysorbate 60, J. Control. Release 254 (2017) 5564 https://doi.org/10.1016/j.jconrel.2017.03.386.

[10] M. Mashal, N. Attia, C. Soto-Sánchez, G. Martínez-Navarrete, E. Fernández, G. Puras, J.L. Pedraz, Non-viral vectors based on cationic niosomes as efficient gene delivery vehicles to central nervous system cells into the brain, Int. J. Pharm. 552(1-2) (2018) 48-55 https://doi.org/10.1016/j.ijpharm.2018.09.038.

[11] N. Attia, M. Mashal, C. Soto-Sánchez, G. Martínez-Navarrete, E. Fernández, S. Grijalvo, R. Eritja, G. Puras, J.L. Pedraz, Gene transfer to rat cerebral cortex mediated by polysorbate 80 and poloxamer 188 nonionic surfactant vesicles, Drug Des. Dev. Ther. 12 (2018) 3937 https://doi.org/10.2147/DDDT.S178532.

[12] S.L. Law, T.C. Chuang, M.C. Kao, Y.S. Lin, K.J. Huang, Gene transfer mediated by sphingosine/dioleoylphosphatidylethanolamine liposomes in the presence of poloxamer 188, Drug Deliv. 13 (2006) 61-67 https://doi.org/10.1080/ 10717540500309024.

[13] G. Kokotos, R. VergeR, A. Chiou, Synthesis of 2-oxo amide triacylglycerol analogues and study of their inhibition effect on pancreatic and gastric lipases, Chem. Eur. J. 6 (22) (2000) 4211-4217 https://doi.org/10.1002/15213765(20001117)6:22\%3c4211: :AID-CHEM4211\% 3e3.0.CO;2-\#.

[14] E. Ojeda, M. Agirre, I. Villate-Beitia, M. Mashal, G. Puras, J. Zarate, et al., Elaboration and physicochemical characterization of niosome-based nioplexes for gene delivery purposes, Non-Viral Gene Delivery Vectors, Humana Press, New York, NY, 2016, pp. 63-75 https://doi.org/10.1007/978-1-4939-3718-9_5. 
[15] E. Ojeda, G. Puras, M. Agirre, J. Zárate, S. Grijalvo, R. Pons, et al., Niosomes based on synthetic cationic lipids for gene delivery: the influence of polar headgroups on the transfection efficiency in HEK-293, ARPE-19 and MSC-D1 cells, Org. Biomol. Chem. 13 (4) (2015) 1068-1081 https://doi.org/10.1039/c4ob02087a.

[16] N. Attia, E. Santos, H. Abdelmouty, S. Arafa, N. Zohdy, R.M. Hernández, et al., Behaviour and ultrastructure of human bone marrow-derived mesenchymal stem cells immobilised in alginate-poly-I-lysine-alginate microcapsules, J. Microencapsul. 31 (6) (2014) 579-589 https://doi.org/10.3109/02652048.2014.898706.

[17] G. Puras, M. Mashal, J. Zarate, M. Agirre, E. Ojeda, S. Grijalvo, et al., A novel cationic niosome formulation for gene delivery to the retina, J. Control. Release 174 (2014) 27-36 https://doi.org/10.1016/j.jconrel.2013.11.004.

[18] S. Eastman, C. Siegel, J. Tousignant, A. Smith, S. Cheng, R. Scheule, Biophysical characterization of cationic lipid: DNA complexes, Biochim. Biophys. Acta 1325 (1) (1997) 41-62 https://doi.org/10.1016/S0005-2736(96)00242-8.

[19] I. Cacciotti, C. Ceci, A. Bianco, G. Pistritto, Neuro-differentiated Ntera2 cancer stem cells encapsulated in alginate beads: first evidence of biological functionality, $\begin{array}{lllllll}\text { Mater Sci Eng C Mater Biol Appl } 81 & \text { (2017) 32-38 }\end{array}$ https://doi.org/10.1016/j.msec.2017.07.033.

[20] N.C. Manley, R.L. Azevedo-Pereira, T.M. Bliss, G.K. Steinberg, Neural stem cells in stroke: intracerebral approaches, Cell Therapy for Brain Injury, Springer, Cham, 2015, pp. 91-109 https://doi.org/10.1007/978-3-319-15063-5_7.

[21] E. Binello, I.M. Germano, Stem cells as therapeutic vehicles for the treatment of high-grade gliomas, Neuro Oncol. 14 (3) (2011) 256-265.

[22] M.J. Tsai, C.F. Weng, S.K. Shyue, D.Y. Liou, C.H. Chen, C.W. Chiu, et al., Dual effect of adenovirus-mediated transfer of BMP7 in mixed neuron-glial cultures: neuroprotection and cellular differentiation, J. Neurosci. Res. 85 (13) (2007) 29502959 https://doi.org/10.1002/jnr.21395.

[23] P. Benda, J. Lightbody, G. Sato, L. Levine, W. Sweet, Differentiated rat glial cell strain in tissue culture, Science 161 (3839) (1968) 370-371 https://doi.org/10. 1126/science. 161.3839.370.

[24] Y. Guan, J. Chen, Y. Zhan, H. Lu, Effects of dexamethasone on C6 cell proliferation, migration and invasion through the upregulation of AQP1, Oncol Lett 15 (5) (2018) 7595- 7602 https://doi.org/10.3892/ol.2018.8269.

[25] A. Caricasole, D. Ward-van Oostwaard, L. Zeinstra, A. Van Den Eijnden-Van Raaij, C. Mummery, Bone morphogenetic proteins (BMPs) induce epithelial differentiation of NT2D1 human embryonal carcinoma cells, Int. J. Dev. Biol. 44 (5) (2003) 443-450 PMI D: 11032177.

[26] J.L. Tso, S. Yang, J.C. Menjivar, K. Yamada, Y. Zhang, I. Hong, Y. Bui, A. Stream, W.H. McBride, L.M. Liau, S.F. Nelson, Bone morphogenetic protein 7 sensitizes $\mathrm{O}^{6}$-methylguanine methyltransferase expressing-glioblastoma stem cells to clinically relevant dose of temozolomide, Mol. Cancer 14 (1) (2015) 189 https: //doi.org/10.1186/s12943-015-0459-1.

[27] Z. Li, Q. Zhong, H. Liu, P. Liu, J. Wu, D. Ma, et al., Conditioned medium from neural stem cells inhibits glioma cell growth, Cell. Mol. Biol. 62 (12) (2016) 68-73 https: // doi.org/10.14715/cmb/2016.62.12.12.

[28] S.R. Chirasani, A. Sternjak, P. Wend, S. Momma, B. Campos, I.M. Herrmann, et al., Bone morphogenetic protein-7 release from endogenous neural precursor cells suppresses the tumourigenicity of stem-like glioblastoma cells, Brain 133 (7) (2010) 1961- 1972 https://doi.org/10.1093/brain/awq128.

[29] L. Caja, C. Bellomo, A. Moustakas, Transforming growth factor $\beta$ and bone morphogenetic protein actions in brain tumors, FEBS Lett. 589 (14) (2015) 15881597 https://doi.org/10.1016/j.febslet. 2015.04.058.

[30] K.S. Lau, The Role of Bone Morphogenetic Protein 2 in Ovarian Cancer Migration, Doctoral dissertation, University of British Columbia, 2016, https: //dx.doi.org/10.14288/1.0307514. 
[31] K. Savary, D. Caglayan, L. Caja, K. Tzavlaki, S.B. Nayeem, T. Bergström, et al., Snail depletes the tumorigenic potential of glioblastoma, Oncogene 232 (47) (2013) 5409-5420 https://doi.org/10.1038/onc.2013.67. 